\title{
Towards port infrastructure adaptation: a global port climate risk analysis
}

\author{
Kana Mutombo $^{1} \cdot$ Aykut Ölçer $^{1}$
}

Received: 7 March 2016 / Accepted: 8 September 2016/Published online: 20 September 2016

(C) World Maritime University 2016

\begin{abstract}
In this paper, a new concept of "port climate risk exposure function along the sea-land boundary axis" is introduced as a critical component towards port adaptation. This concept derived from a global survey which was conducted over 29 countries to assess perceived climate risks to port infrastructure from relevant experts. The methodology used 48 climate scenarios developed based on existing data. Ultimately, this paper serves as a global climate risk indicator to guide further adaptive initiatives in ports.
\end{abstract}

Keywords Port infrastructure $\cdot$ Adaptation $\cdot$ Risk $\cdot$ Climate change

\section{Background}

In December 2015, a new agreement was negotiated at the COP 21 conference in Paris and this has globally raised hope and confidence in the world leadership commitment to fight climate change. Moreover, climate inertia is unfortunately adding further complexity ("Thermal Inertia and Climate," 2005; Vogt-Schilb, Meunier, \& Hallegatte, 2012) to the current impasse. Despite the global commitment to reduce GHG, it is expected that climate will still continue to change for a long period before it reaches a state of equilibrium (Becker, Inoue, Fischer, \& Schwegler, 2012; Hansen et al., 2013; IPCC, 2014; Plattner, 2009; Rosenschöld, Rozema, \& Frye-Levine, 2014; Tebaldi \& Friedlingstein, 2013). Sea level rise, droughts, floods, increase heat, intense storm and waves will still be experienced throughout a good part of the present century. This prompts the need for port adaptation, given that seaports are located in areas highly vulnerable to climate variations (Becker et al., 2011; Villatoro et al., 2014; Arns, Wahl, Haigh, Jensen, \& Pattiaratchi, 2013; Demirbilek, 2013; PIANC, 2008; Nursey-Bray et al., 2013).

Kana Mutombo

p1306@wmu.se; http://www.wmu.se

Aykut Ölçer

aio@wmu.se; http://people.wmu.se/olcer

1 World Maritime University, Fiskehamnsgatan 1, P O Box 500, SE-20124 Malmö, Sweden 
Meanwhile, while there is a wide recognition for the need to adapt seaports to climate change (Rosenberg et al., 2010; Mcevoy \& Mullett, 2014; Becker et al., 2013; "Climate Change and Adaptation Planning for Ports," 2015; Nursey-Bray \& Miller, 2011; Wright, 2013; Kintisch, 2008; Karambas, 2014; Dawson, 2008), silo decisionmaking approach in adaptation initiatives has largely led to the prevailing ineffectiveness of solutions in the industry. This paper analyses global trends on the perceived climate risks in ports with the view to serve as a high-level guideline indicator towards adaptation at ports.

\section{Methodology}

\subsection{Port infrastructure}

Port infrastructure forms part of the built environment. They are created by humans to achieve specific functions, and they are expected to have a useful life of 50 to 100 years depending on the design criteria. Since they are conceived by humans during early planning stage of projects, it is paramount that provision to prepare-adapt-respond to climate change (in the wider context of logistic supply chain) be factored during their conceptual stages in order to alleviate or minimise any possible future adaptation which is generally costly and extremely disrupting.

There is currently a large disparity in the literature in respect to the definition of port infrastructure. This ranges from physical port assets to notions that include soft assets such as operating procedures, management practices and development policies ("Sea Port Infrastructure Maintenance Expenditure," 2015; Flor \& Defilippi, n.d; "Investment in Sea Port Infrastructure," 2013; Haralambides, n.d.; Taneja, Vellinga, $\&$ Sol, 2014). In terms of the physical assets, there is a strong tendency to regroup port infrastructure into six (6) families of basic assets (Tsinker, 1997; Bruun, 2005; Beatley \& Wright, 2001; Høgedal, Knudsen, \& Lassen, 2001; Homer, Law, \& Molyneaux, 2015) vulnerable to the effect of climate change (RMIT University, 2013): berthing structures, protection barriers, port superstructure, channels and harbours, road and rail networks. The term port infrastructure in this paper refers and is limited only to the above families of assets.

\subsection{Climate variables}

A study by RMIT University1, ed., (2013) concluded that climate variables which would affect long-term performance of the port infrastructure were identified as sea level rise, water table, temperature, rainfall/runoff, wave, wind, salinity and humidity. This research will therefore be limited to the abovementioned climate variables which are most relevant to port.

\subsection{Climate narrative}

In order to respond to the needs of decision-makers to assess climate risks in ports, climate data projections from a statically downscaled and spatial interpolation methods present significant limitations. The main tools used to project climate are general 
circulation models (GCMs), which are computer models that mathematically represent various physical processes of the global climate system ("Global Climate Change," n.d.). Processes in this system are generally well known but difficult to be reliably transposed into a localised-port-specific model due to the unique characteristics of each port-city region. Thus, GCM should ideally be considered only at global or continental scales for climatic conditions at longer time scales. For finer spatial and temporal scales, a downscaling process is necessary. This process relies on the assumption that local climate is a combination of large-scale climatic/atmospheric features (global, hemispheric, continental, regional) and local conditions such as topography, water bodies and land surface properties ("Global Climate Change," n.d.). Representation of the local conditions requires additional local-based information, data and assumptions which are generally beyond the capacity of current GCMs. This has led to further uncertainties and limitations of the results.

Because each port is unique and located in distinctive geographical locations (PIANC 2014), it makes it difficult to develop a climatic representation that fits all port geographical and climatic conditions. For this reason, a standard climate narrative is essential to assess port risk, vulnerability and resilience. Impact on ports will be measured based on a standard medium-term variation in climate indices from existing prevailing climatic conditions at corresponding ports. Standard variations in climate indices are considered as the basis for developing a climate narrative to be used across all ports, and consequences of such change on port infrastructure and on logistic supply chain will then be assessed.

Existing predictions from IPCC, ${ }^{1} \mathrm{NRC},{ }^{2} \mathrm{USACE}^{3}$ and $\mathrm{NOAA}^{4}$ (IPCC, 2014; PIANC, 2014; Nicholls, et al., 2008) were assessed and were found to have significant disparities in their results. Meanwhile, results from these assessments highlight visible and clear trends for sea level and temperature-related indices and this is reflecting on the climate narrative developed (Table 1). However, trends on rainfall, wave, wind, salinity, humidity and water table remain extremely uncertain with large disparity. From existing recorded measurements, prediction variations on these variables exceed sometimes the $100 \%$ range from one port to another. This is largely attributed to the close dependence of these variables to port local conditions which are very difficult to factor into climate models. Given the preventive nature of risk assessment approach and for the purpose of this research, larger projection ranges (50\% increase) are used on the standard climate narrative (Table 1) as a conservative way to factor uncertainty for rainfall, wave, wind, salinity, humidity and water table. However, in practical term, when assessing climate risk in specific ports, it is recommended that each port develops its unique and realistic climate narrative that suits local conditions.

\subsection{Scenarios}

The development of scenarios facilitates communication on climate risks (LTAS, 2015). A scenario in this paper is defined as the exposure of a port family asset to a

\footnotetext{
${ }^{1}$ Intergovernmental Panel on Climate Change

${ }^{2}$ National Research Council

${ }^{3}$ United States Army Corps of Engineers

${ }^{4}$ National Oceanic and Atmospheric Administration
} 
Table 1 Climate narrative

\begin{tabular}{lll}
\hline Climate variables & Unit & $\begin{array}{l}\text { Projected medium-term } \\
\text { variation }\end{array}$ \\
\hline Sea level & $\mathrm{m}$ & 0.75 \\
Ground water & $\mathrm{m}$ & 5 \\
Temperature & Degree C & 1 \\
Precipitation & $\%$ & 50 \\
Wave height & $\%$ & 50 \\
Wind speed & $\%$ & 50 \\
Salinity & $\%$ & 50 \\
Humidity & $\%$ & 50 \\
\hline
\end{tabular}

particular climate variable event. In this respect, the number of scenarios considered in this paper is as follows:

\section{Equation 1: calculation of number of scenarios}

8Climate variables $\times 6$ port infrastructure families $=48$ scenarios

This paper aims at presenting the results of the survey conducted with the view to analyse the trends on the perceived climate risks at ports globally. The survey conducted sought at gathering the views of port experts on the risk and vulnerability associated with 48 standard climate narrative scenarios (Fig. 1) at their respective ports. Based on evaluation and trends, results are

\begin{tabular}{|c|c|c|c|c|c|c|c|c|}
\hline 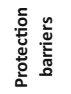 & 1 & 2 & 3 & 4 & 5 & 6 & 7 & 8 \\
\hline 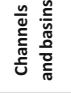 & 9 & 10 & 11 & 12 & 13 & 14 & 15 & 16 \\
\hline 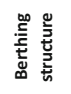 & 17 & 18 & 19 & 20 & 21 & 22 & 23 & 24 \\
\hline 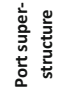 & 25 & 26 & 27 & 28 & 29 & 30 & 31 & 32 \\
\hline 휴 & 33 & 34 & 35 & 36 & 37 & 38 & 39 & 40 \\
\hline \multirow[t]{2}{*}{ 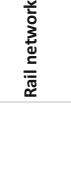 } & 41 & 42 & 43 & 44 & 45 & 46 & 47 & 48 \\
\hline & $\begin{array}{c}\text { Sea level } \\
\text { variation of } \\
0.75 \mathrm{~m}\end{array}$ & $\begin{array}{c}\text { 5m variation } \\
\text { in Water } \\
\text { table }\end{array}$ & $\begin{array}{l}\text { Temperatu } \\
\text { variation } \\
\text { 1deg.C }\end{array}$ & $\begin{array}{l}50 \% \text { variatio } \\
\text { in Rainfall }\end{array}$ & $\begin{array}{l}50 \% \text { variati } \\
\text { in Wave } \\
\text { heights }\end{array}$ & $\begin{array}{r}50 \% \text { variati } \\
\text { in Wind } \\
\text { speed }\end{array}$ & $\begin{array}{l}50 \% \text { variati } \\
\text { in Salinit }\end{array}$ & $\begin{array}{l}50 \% \text { variati } \\
\text { in Humidi }\end{array}$ \\
\hline
\end{tabular}

Fig. 1 Forty-eight scenarios' representation 
then analysed. This shall ultimately serve as the basis for developing a framework for adaptation.

\section{Survey questionnaire}

In recent decades, in order to gain competitive advantage, it is increasingly becoming essential to focus on logistic chain as a way of reducing the price of goods (PIANC, 2014). Efficiency on the logistic chains has nowadays become the main drivers for trade (Liu and Lam 2015). Ports, as essential players in the logistic chains, are increasingly expected to fulfil seamless logistic chain requirements (Gaur 2006). This has resulted in a gradual shift from assessing risk within the port boundaries to a larger scale within logistic chain.

In this study, risk is defined as the probability of affecting smooth running of the port logistic service (movement of goods) as a result of climate scenario. The survey questionnaire was developed with the view to assess the perceived risk associated with each of the 48 scenarios in different ports from various relevant experts. It was designed in such a way that each identified high-risk scenario triggers a subsequent drop-down question. This sub-question aims at assessing vulnerability by evaluating the existing capacity to deal with the identified risk. High-risk scenarios were also subjected to further scrutiny by evaluating whether the port has provision for any redundancy in the system in order to allow seamless port logistic services.

Closed questions were used and answers were to be selected among five given options: "Not relevant", "Low risk", "Medium risk", "High risk" and "I don't know" in respect to the first part of the questionnaire relating to "RISK EVALUATION". The second part titled "EVALUATION OF ALTERNATIVES/ REDUNDANCY” only focuses on high-risk scenarios from part 1. High-risk scenario responses from part 1 triggered an additional drop-down question. The additional question served to evaluate whether there was any provision for redundancy/alternatives. Respondents were therefore provided with two options: "Yes" or "No". On the third part of the survey titled "RESILIENCE MEASUREMENT", high-risk scenarios from part 1 are assessed to evaluate the approximate time required to repair and bring the infrastructure to its original functionality. Seven options were provided for selection: "Less than 1 month", "1 to 2 months", "2 to 3 months", "3 to 4 months", "4 to 5 months", "5 to 6 months" and "greater than 6 months". In addition, at the end of the survey, an optional open question was used to seek respondents' general comments on the survey but a very poor participation of less than $5 \%$ was unfortunately recorded in this respect.

The survey questionnaire layout is illustrated in Fig. 2.

\section{Survey participation}

As the researcher is a member of PIANC5, the survey was primarily disseminated via a link on SurveyGizmo to all PIANC members. Additionally, current 


\section{QUESTIONNAIRE LAYOUT}

RISK EVALUATION: Over the next 50 years, what level of risk do the following scenarios pose to the proctection barriers at your port, should they occur:

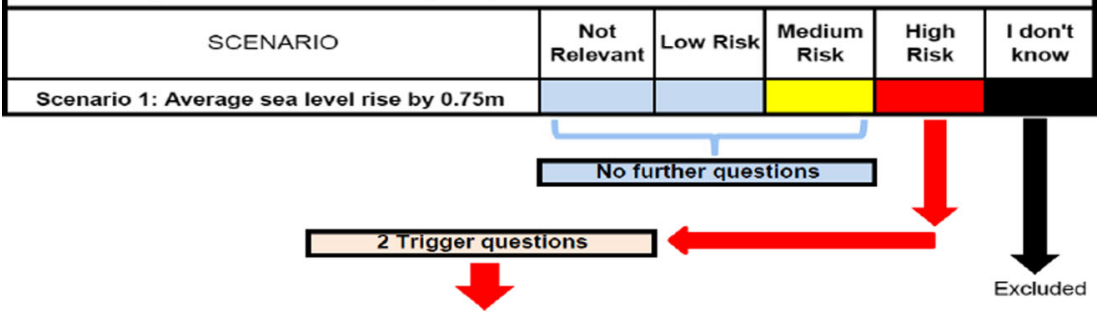

EVALUATION OF ALTERNATIVES / REDUNDANCY: In respect to scenario 1, if protection barriers are affected, advise whether there is redundancy / alternative measure to perform similar function and maintain port logistic service NO there is no alternative
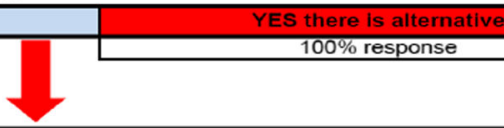

RESILIENCE MEASUREMENT: In respect to scenario 1, please evaluate approximately the anticipated time required to adjust / repair the protection barrier in order to bring it back to its basic functionality.

\begin{tabular}{|c|c|c|c|c|c|c|}
\hline \multicolumn{9}{|c|}{ Months } \\
\hline Less than 1 & $\mathbf{1 - 2}$ & $\mathbf{2 - 3}$ & $\mathbf{3 - 4}$ & $\mathbf{4 - 5}$ & $\mathbf{5 - 6}$ & Greater than 6months \\
\hline \multirow{2}{*}{6 responses } & $0 \%$ & $0 \%$ & $0 \%$ & $0 \%$ & $33.34 \%$ & $66.66 \%$ \\
\hline
\end{tabular}

Fig. 2 Survey questionnaire layout

WMU6 master students and alumni groups were contacted via email to assist with further dissemination to the relevant experts in their respective ports. The survey opened on 11 May 2015 and closed on 29 July 2015. Given that the survey was conducted online and disseminated to PIANC ${ }^{5}$ members via PIANC global secretariat in Brussels, it is impossible to determine with accuracy the actual response rate. Nevertheless, based on SurveyGizmo online record, from a total of 115 potential participants who had at least clicked on the survey link, we have received 69 responses of which 50 were valid, representing an impressive virtual response rate of $43.5 \%$.

Table 1 provides details of survey participants, and the participation distribution was fairly equitable and satisfactory as shown in Fig. 3.

\section{Survey results: data processing and interpretation}

\subsection{Risk evaluation}

For risk evaluation, a Likert scale from 0 to 3 was introduced to facilitate data processing with $0,1,2$ and 3 representing, respectively, "Not relevant", "Low", "Medium" and "High risk". In order to ensure fair representation of results, all "I don't know" responses (representing in red on Table 2) were omitted from the

\footnotetext{
$\overline{5}$ The World Association for Waterborne Transport Infrastructure (www.pianc.org)
} 


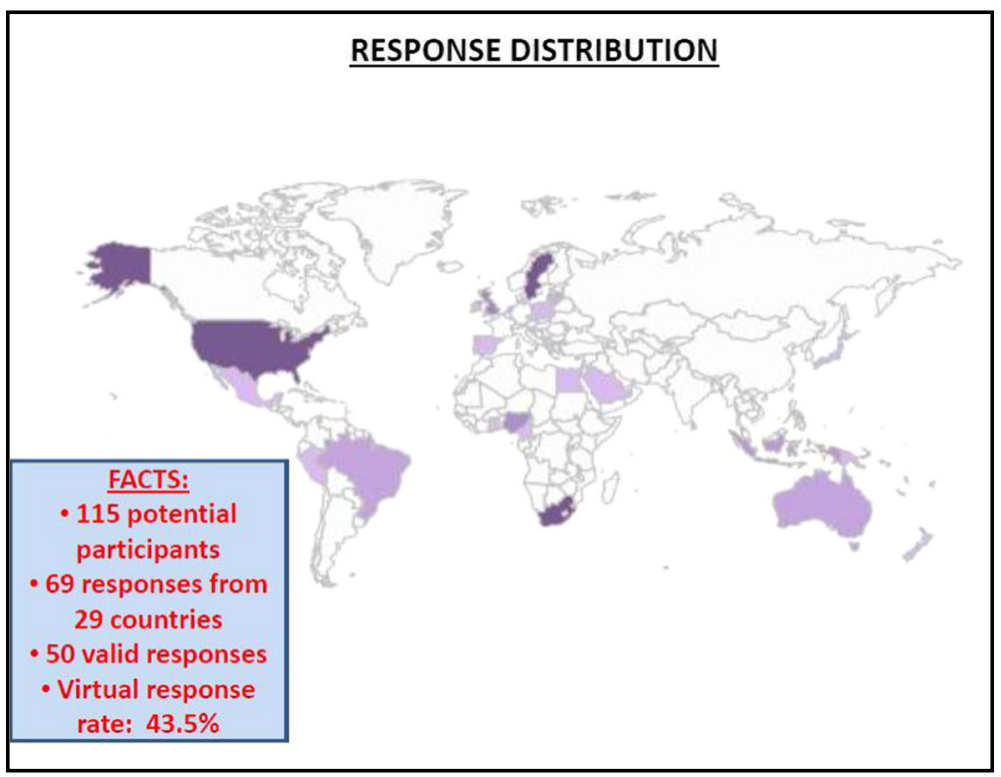

Fig. 3 Participation distribution

scale and disregarded. This practice assisted in improving accuracy of results during data processing and it also led to different response rates for the different scenario questions. For each scenario, using a Likert scale, a mean score could then be calculated.

The graphical representation (Fig. 4) suggests that, with respect to climate change, industry is generally concerned about the impact of wave and wind force variation on protection barriers in ports. This trend also reinforces the general prevailing sentiment across the industry that climate extremes (often a combination of wind and wave at extreme proportion) are the main climate concern (PIANC, 2009) in ports. However, it is worth placing on record that the above results are only a representation of a global trend. Given the particularity of each port, there are certainly ports that may in fact present different climate risk configurations. As such, it should be noted that this information should therefore be considered as a high-level guideline to assist ports in developing specific solution-focussed initiatives to climate change.

\subsection{Evaluation of alternative (redundancy) and resilient measurement}

Judging from survey responses, for all high-risk scenarios, there are no alternative or redundancy for maintaining smooth logistic services. Based on responses to triggered question 3, for all high-risk scenarios, repairs (in order to bring back the port infrastructure to its original functionality) will take a minimum of 5 months or longer. Given that vulnerability and resiliency of the port logistic system are, respectively, defined by the provision of alternative and ability to recover promptly (PIANC, 2014), all high-risk scenarios therefore 
Table 2 Survey participation

\begin{tabular}{|c|c|c|}
\hline Country & No. & Percent $(\%)$ \\
\hline South Africa & 17 & 24.6 \\
\hline USA & 9 & 13.0 \\
\hline Nigeria & 4 & 5.8 \\
\hline Kenya & 4 & 5.8 \\
\hline Indonesia & 4 & 5.8 \\
\hline Portugal & 3 & 4.4 \\
\hline Brazil & 3 & 4.4 \\
\hline UK & 2 & 2.9 \\
\hline Netherlands & 2 & 2.9 \\
\hline Egypt & 2 & 2.9 \\
\hline Peru & 1 & 1.5 \\
\hline Angola & 1 & 1.5 \\
\hline Poland & 1 & 1.5 \\
\hline Saudi Arabia & 1 & 1.5 \\
\hline Thailand & 1 & 1.5 \\
\hline Sweden & 1 & 1.5 \\
\hline Papua New Guinea & 1 & 1.5 \\
\hline Sri Lanka & 1 & 1.5 \\
\hline Gambia, The & 1 & 1.5 \\
\hline Cameroon & 1 & 1.5 \\
\hline Panama & 1 & 1.5 \\
\hline Australia & 1 & 1.5 \\
\hline Guatemala & 1 & 1.5 \\
\hline Brunei & 1 & 1.5 \\
\hline Latvia & 1 & 1.5 \\
\hline Jamaica & 1 & 1.5 \\
\hline Italy & 1 & 1.5 \\
\hline Mexico & 1 & 1.5 \\
\hline \multirow[t]{2}{*}{ Ireland } & 1 & 1.5 \\
\hline & 69 & \\
\hline
\end{tabular}

present high vulnerability and low resiliency in the context of the port logistic system, a major cause of concern.

\subsection{Trend analysis}

It was found from Fig. 5 that port climate risk score is higher on sea side and gradually reducing towards land side. Moreover, due to each port unique configuration, it is difficult to allocate firm distances along the $X$ axis for each family asset. Therefore, reduction in climate risk score from sea to land boundary of port cannot be represented in terms of regression, although the graph on figure clearly suggests a progressive and 


\begin{tabular}{|c|c|c|c|c|c|c|c|c|}
\hline \multicolumn{9}{|c|}{ GLOBAL CLIMATE RISK IN PORT PER SCENARIO } \\
\hline \multirow{7}{*}{ 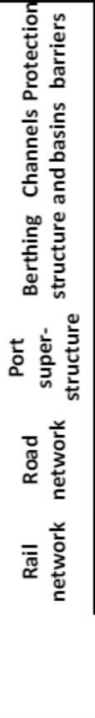 } & 1 & 2 & 3 & 4 & 5 & 6 & 7 & 8 \\
\hline & 9 & 10 & 11 & 12 & 13 & 14 & 15 & 16 \\
\hline & 17 & 18 & 19 & 20 & 21 & 22 & 23 & 24 \\
\hline & 25 & 26 & 27 & 28 & 29 & 30 & 31 & 32 \\
\hline & 33 & 34 & 35 & 36 & 37 & 38 & 39 & 40 \\
\hline & 41 & 42 & 43 & 44 & 45 & 46 & 47 & 48 \\
\hline & $\begin{array}{c}\text { Sea level } \\
\text { variation of } \\
0.75 \mathrm{~m}\end{array}$ & $\begin{array}{c}\quad 5 \mathrm{~m} \\
\text { variation in } \\
\text { Water table }\end{array}$ & $\begin{array}{c}\text { Temperatur } \\
\text { e variation } \\
\text { of } 1 \text { deg.C }\end{array}$ & $\begin{array}{c}50 \% \\
\text { variation } \\
\text { in Rainfall }\end{array}$ & $\begin{array}{c}50 \% \\
\text { variation in } \\
\text { Wave } \\
\text { heights }\end{array}$ & $\begin{array}{c}\quad \mathbf{5 0} \% \\
\text { variation in } \\
\text { Wind speed }\end{array}$ & $\begin{array}{c}\mathbf{5 0} \% \\
\text { variation in } \\
\text { Salinity }\end{array}$ & $\begin{array}{c}\mathbf{5 0 \%} \\
\text { variation in } \\
\text { Humidity }\end{array}$ \\
\hline Lou & risk & & Mediu & m risk & & High & risk & \\
\hline
\end{tabular}

Fig. 4 Results of global climate scenario based on average mean score

significant reduction in risk score from sea to land boundaries. An illustration of this climate risk exposure along the sea-land boundary axis is clearly shown in Fig. 6.

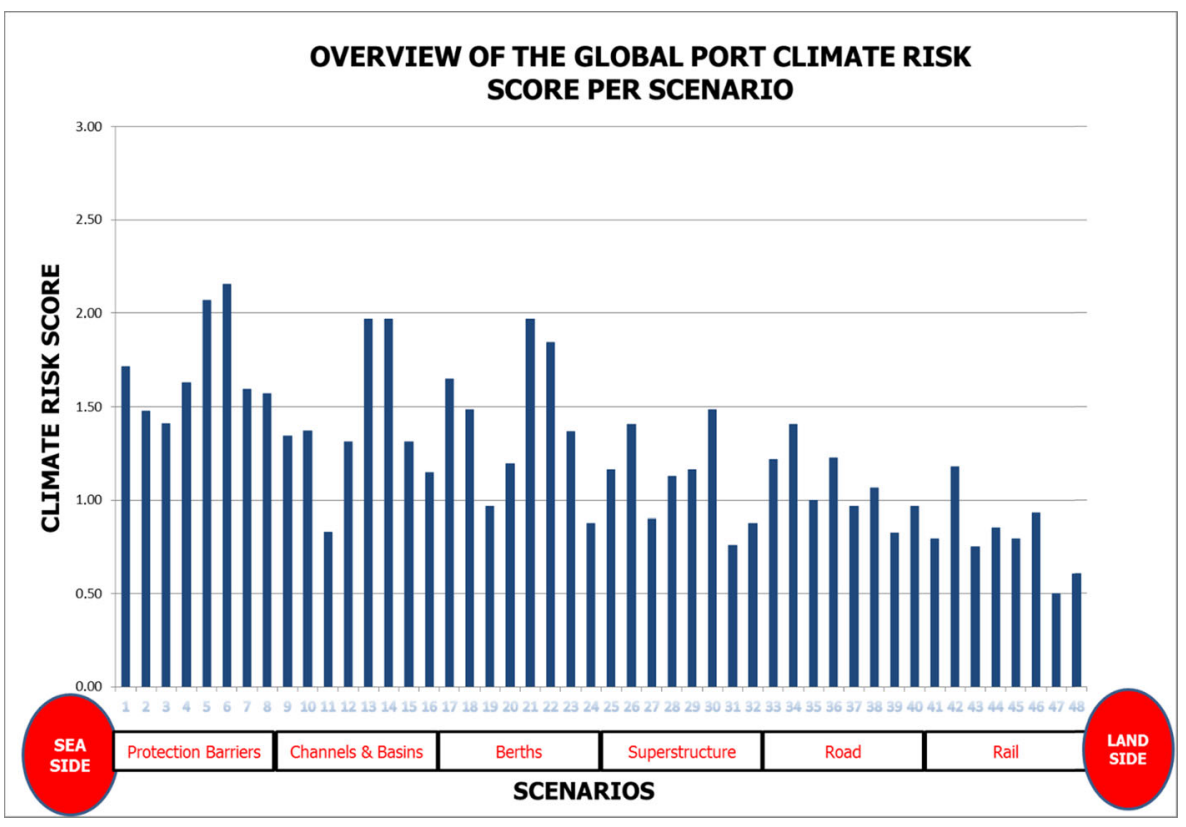

Fig. 5 Global port climate risk score per scenario 

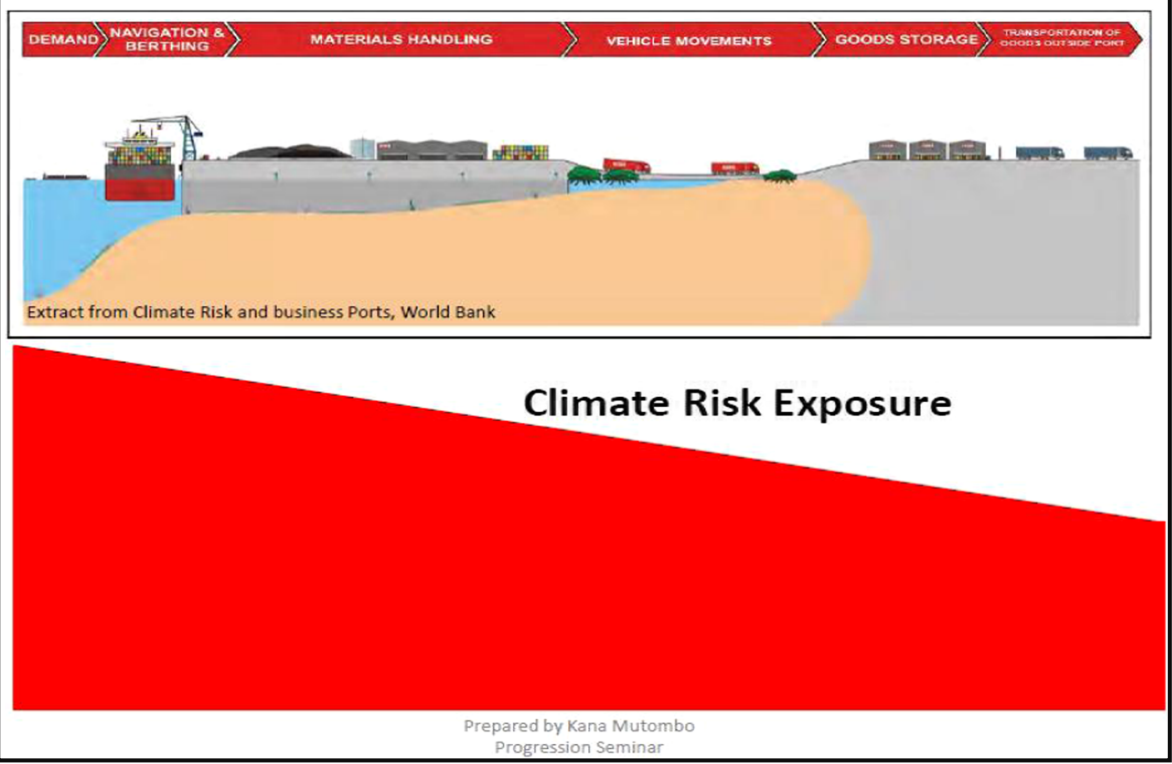

Fig. 6 Illustration of sea-land boundary axis

Additionally, as shown in Fig. 7, changes in wind, wave, ground water, sea level rise and precipitation are port's biggest climate concerns, scoring, respectively, $1.58,1.49,1.39,1.31$ and 1.22 . On the contrary, changes in salinity, humidity and temperature are relatively classified as low risk in ports, scoring, respectively, $1.06,1.01$ and 0.98 . The top two port climate concerns are wind and

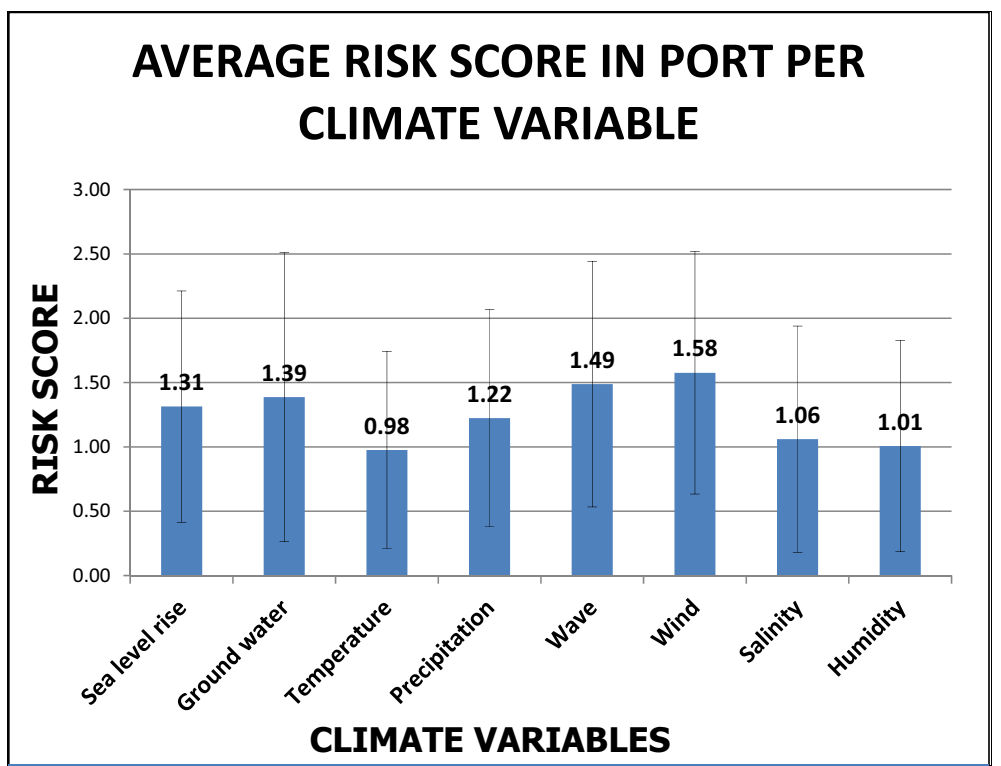

Fig. 7 Global average risk score per climate variable 
wave; a tendency that reflects largely in many literature (Hunter, Church, White, \& Zhang, 2013; PIANC 2014; IPCC 2014) as climate extreme.

\section{Conclusion}

The climate risk exposure along the sea-land boundary axis is critical in steering the way climate adaptation investments are allocated in ports. Furthermore, it should trigger new way of thinking with respect to port planning and design approaches. This information should influence by large port configuration during the early stage of development and it could provide significant guidance for design engineers when factoring climate change in infrastructure design calculations. Traditionally, approach to infrastructure design is based on an optimal solution for the worst possible case scenario plus a standard safety factor. New approach taking into consideration a climate safety factor which will be dependent on the position of the infrastructure along the sea-land port axis could therefore be essential.

In the light of this, since climate risk sensitivity differs from port to port, it is encouraged that each port determines its unique sea-land port boundary axis with regression by taking into consideration infrastructure distance measurements and develop a function of risk along such axis. However, in smaller ports with limited resources or in a port where climate change is not perceived as a major threat, in the absence of a specific sea-land climate risk function, the above general function in Fig. 5 could be very useful for guidance.

Meanwhile, it is worthwhile mentioning that this study is conducted based on perceptions of risks which could be vastly subjective. It is therefore recommended that, when assessing climate risk score, each port should consider various techniques (e.g. Delphi) in order to minimise subjectivity and increase reliability of results.

\section{References}

Arns A, Wahl T, Haigh I, Jensen J, Pattiaratchi C (2013) Estimating extreme water level probabilities: a comparison of the direct methods and recommendations for best practise. Coast Eng 81:51-66. doi:10.1016/j.coastaleng.2013.07.003

Beatley, D. K., \& Wright, N. T. (2001). Applying information technology to maintenance of aging port infrastructure. Ports '01. doi:10.1061/40555(2001)74

Becker, A., Fischer, M., Schwegler, B., \& Inoue, S. (2011). Considering climate change: a survey of global seaport administrators (Rep.). Stanford: Stanford University. Retrieved January 14, 2014, from http:// http://www.pianc.org/downloads/climate\%20change/WP128.pdf

Becker, A., Inoue, S., Fischer, M., \& Schwegler, B. (2012). Climate change impacts on international seaports: knowledge, perceptions, and planning efforts among port administrators. Climatic Change, 110(1-2), 529. Retrieved May 7, 2014, from http://search.proquest.com.proxy.wmu.se/docview/ 909755863 ?accountid $=43722$

Becker AH, Acciaro M, Asariotis R, Cabrera E, Cretegny L, Crist P, Velegrakis AF (2013) A note on climate change adaptation for seaports: a challenge for global ports, a challenge for global society. Clim Chang 120(4):683-695. doi:10.1007/s10584-013-0843-Z

Bruun, P. (2005). Introduction: [port and coastal engineering: developments in science and technology]. Journal of Coastal Research, Special Issue No. 46. Port and Coastal Engineering: Developments in Sci Technol, 1-21. Retrieved July 30, 2016, from http:/www.jstor.org/stable/10.2307/25737339?ref = searchgateway:6131195a2c20f1e5703ced1cb7ce834c 
Climate Change and Adaptation Planning for Ports. (2015). doi:10.4324/9781315756813

Dawson AG (2008) Rates and mechanisms of climate change: implications for ports and harbours. WMU J Marit Aff 7(2):467-476. doi:10.1007/bf03195145

Demirbilek Z (2013) Sea level rise and impacts on engineering practice. Ocean Eng 71:1-2. doi:10.1016/j.oceaneng.2013.07.002

Flor L, Defilippi E (n.d) Port infrastructure. Port Management. doi:10.1057/9781137475770.0012

Gaur, P. (2006). Port planning as a strategic tool: A typology (Master's thesis, Institute of Transport and Maritime Management Antwerp, University of Antwerp, 2005). Paris: The World Bank. Retrieved March 05, 2014, from http://nweb90.worldbank.org/exteu/SharePapers.nsf/(all)/F1A12C37A9384 D528525722B005B767A/File/PORT+PLANNING+AS+A+STRATEGIC+TOOL.PDF

Global Climate Change. (n.d.). Retrieved from https:/www.climatelinks.org/resources/review-downscalingmethods-climate-change-projections

Hansen J, Kharecha P, Sato M, Masson-Delmotte V, Ackerman F, Beerling DJ, Zachos JC (2013) Assessing "dangerous climate change": required reduction of carbon emissions to protect young people, future generations and nature. PLoS One 8(12). doi:10.1371/journal.pone.0081648

Haralambides, H. E. (n.d.). Competition, excess capacity and the pricing of port infrastructure. Port Management. doi:10.1057/9781137475770.0014

Høgedal, M., Knudsen, A., \& Lassen, B. (2001). POMS: an internet-based system for port maintenance and management. Ports '01. doi:10.1061/40555(2001)75

Homer, R. M., Law, D. W., \& Molyneaux, T. C. (2015). Probability distribution functions for cover used in 3D model simulating concrete deterioration in port assets. J. Phys.: Conf. Ser. Journal of Physics: Conference Series, 628, 012038. doi:10.1088/1742-6596/628/1/012038

Hunter J, Church J, White N, Zhang X (2013) Towards a global regionally varying allowance for sea-level rise. Ocean Eng 71:17-27. doi:10.1016/j.oceaneng.2012.12.041

Investment in sea port infrastructure. (2013). doi:10.1787/9789282103937-table79-en

IPCC WGII AR5. (2014). Fifth assessment report-impacts, adaptation and vulnerability. Retrieved November 11, 2014, from http://www.ipcc.ch/report/ar5/wg2/

Karambas TV (2014) Modelling of climate change impacts on coastal flooding/erosion, ports and coastal defence structures. Desalin Water Treat 54(8):2130-2137. doi:10.1080/19443994.2014.934115

Kintisch E (2008) Global change: roads, ports, rails aren't ready for changing climate, says report. Science 319(5871):1744-1745. doi:10.1126/science.319.5871.1744

LTAS. (2015). Climate trends and scenarios for South Africa. LTAS Phase 1, Technical Report (no. 1 of 6)

Liu, T., \& Lam, J. S. (2015). Impact of port disruption on transportation network [Scholarly project]. In http://www.academia.edu/7360287/The_impact_of_port_disruption_on_transportation_network. Retrieved June 02, 2015

Mcevoy, D., \& Mullett, J. (2014). Enhancing the resilience of seaports to a changing climate. Palutikof/ Applied Studies in Climate Adaptation Applied Studies in Climate Adaptation, 200-207. doi:10.1002/ 9781118845028.ch22

Nicholls, R. J., Hanson, S., Herweijer, C., Patmore, N., Hallegatte, S., Morlot, J., Wood, R.M. (2008). Ranking port cities with high exposure and vulnerability to climate extremes, OECD Environment Working Papers No.1 (Rep.). Paris, France: OECD publishing. Retrieved from httphttp:/www.keepeek.com/DigitalAsset-Management/oecd/environment/rankingport-cities-with-high-exposure-and-vulnerability-toclimateextremes_011766488208\#page1://

Nursey-Bray M, Miller T (2011) Ports and climate change: building skills in climate change adaptation, Australia. Climate Change and the Sustainable Use of Water Resources Climate Change Management: 273-282. doi:10.1007/978-3-642-22266-5 17

Nursey-Bray M, Blackwell B, Brooks B, Campbell ML, Goldsworthy L, Pateman H, Hewitt CL (2013) Vulnerabilities and adaptation of ports to climate change. J Environ Plan Manag 56(7):1021-1045. doi:10.1080/09640568.2012.716363

PIANC, 2008. Envicom - Task Group 3. Climate change navigation: a review of climate change drivers, impacts, responses and mitigations (Rep.). Retrieved 2013, from PIANC website: http://www.pianc.org/ downloads/envicom/envicom-free-tg3.pdf

PIANC, 2009. Inland waterborne transport: connecting countries (S. Bonnerjee, A. Cann,H. Koethe, D. Lammie, G. Lieven, J. Muskatirovic, et al., Authors) [Cong. Rept. The united Nations World Water Development Report 3]. Paris: UNESCO. Retrieved January 24, 2014, from http://unesdoc.unesco.org/images/0018/001817/181794e.pdf

PIANC, 2014. Sustainable ports: a guide for port authorities. Retrieved November 11, 2014, from http:// pianc.org.au/2014/05/19/release-of-pianc-wg-report-no-150-sustainable-ports-aguide-for-port-authoritiesmay-2014/ 
Plattner G (2009) Climate change: terrestrial ecosystem inertia. Nature Geoscience Nature Geosci 2(7):467468. doi: $10.1038 /$ ngeo570

RMIT University2 (Ed.). (2013). Climate change adaptation guidelines for ports. Reports series: enhancing the resilience of seaports to a changing climate (Rep.). Melbourne, Australia: National Climate Change Adaptation Research Facility. Retrieved March 28, 2014, from http://www.nccarf.edu.au/publications/ enhancing-resilience-seaports-climate-changeadaptation-guidelines

Rosenberg EA, Keys PW, Booth DB, Hartley D, Burkey J, Steinemann AC, Lettenmaier DP (2010) Precipitation extremes and the impacts of climate change on stormwater infrastructure in Washington State. Clim Chang 102(1-2):319-349. doi:10.1007/s10584-010-9847-0

Rosenschöld JM, Rozema JG, Frye-Levine LA (2014) Institutional inertia and climate change: a review of the new institutionalist literature. WIREs Clim Change Wiley Interdisciplinary Reviews: Climate Change 5(5):639-648. doi:10.1002/wcc.292

Sea port infrastructure maintenance expenditure. (2015). doi:10.1787/9789282107782-table105-en

Taneja P, Vellinga T, Sol SR (2014) Planning and management of port infrastructure projects under uncertainty. Vulnerability, Uncertainty, and Risk. doi:10.1061/9780784413609.039

Tebaldi C, Friedlingstein P (2013) Delayed detection of climate mitigation benefits due to climate inertia and variability. Proc Natl Acad Sci 110(43):17229-17234. doi:10.1073/pnas.1300005110

Thermal Inertia and Climate (2005) Science 307(5716):1687d-1687d. doi:10.1126/science.307.5716.1687d

Tsinker GP (1997) Port (harbor) elements: design principles and considerations. Handbook of Port and Harbor Engineering:69-241. doi:10.1007/978-1-4757-0863-9_2

Villatoro M, Silva R, Méndez F, Zanuttigh B, Pan S, Trifonova E, Eftimova P (2014) An approach to assess flooding and erosion risk for open beaches in a changing climate. Coast Eng 87:5076. doi:10.1016/j.coastaleng.2013.11.009

Vogt-Schilb A, Meunier G, Hallegatte S (2012) How inertia and limited potentials affect the timing of sectoral abatements in optimal climate policy. Policy Research Working Papers. doi:10.1596/1813-9450-6154

Wright, S. (2013). Climate change risk management for ports. Ports 2013. doi:10.1061/9780784413067.029 